\title{
From states to events: The acquisition of English passive participles*
}

\author{
MICHAEL ISRAEL, CHRISTOPHER JOHNSON, and \\ PATRICIA J. BROOKS
}

\begin{abstract}
In this paper we examine the development of passive participles in the spontaneous speech of seven English speaking children. We argue that the grammatical properties which distinguish passive participles as a category emerge gradually and are learned as motivated properties of a complex, polysemous construction. The data reveals a regular progression from early adjectival uses to true verbal passives, in which the participle itself denotes a dynamic event. This process follows a consistent pattern, whereby children gradually extend the use of participles to equivocal contexts that are compatible with either a stative or an eventive reading. All seven children regularly use participles in equivocal contexts before they begin to master true verbal passives. This development is analyzed as an instance of constructional grounding, a process whereby certain uses of a relatively simple source construction provide the basis for children's initial hypotheses about a more difficult target construction. More generally, the gradual progression from adjectival to verbal passives suggests how syntactic categories and grammatical constructions can be learned gradually on the basis of earlier, simpler structures.
\end{abstract}

Keywords: language acquisition; passive participles; constructions; usage-based grammar; polysemy; grounding.

\section{Introduction}

English-speaking children as young as 2;11 have been shown to use passive constructions creatively (Brooks and Tomasello 1999). The question is, how do they acquire this ability? This study examines the development of English passive participles as evidenced in the spontaneous productions of seven children in the CHILDES archive (MacWhinney 1995). 
It is well-known that the English passive participle leads a double life (Jespersen 1949; Wasow 1977; Levin and Rappaport-Hovav 1986): sometimes, as in example (1), it acts like an adjective, denoting an ongoing state; sometimes, as in example (2), it acts like a verb, denoting a dynamic event.

(1) a. The stereo has been broken for three weeks now.

b. The children were very scared during the earthquake.

(2) a. The stereo was broken when it fell out the window.

b. The children were scared by the loud crash.

We argue that this ambiguity, which might look like a problem for acquisition, actually provides crucial clues which aid children in mastering the use of participles in passive constructions.

\section{Issues in the development of a grammatical category}

The relation between verbal and adjectival passives has figured prominently in recent debates about language acquisition and the nature of Universal Grammar. For a long time the conventional wisdom was that stative, adjectival participles regularly precede eventive, verbal participles in development. This understanding rested largely on data from elicited production tasks (e.g., Horgan 1978) and experimental studies of comprehension (Maratsos et al. 1985; Sudhalter and Braine 1985). These studies show that while pre-school children do use passive participles, they almost never produce full passives with a $b y$-phrase, and they have difficulty understanding passives in which the participle does not clearly denote a resultant state.

Borer and Wexler (1987) relied heavily on these results to argue against the continuity hypothesis (Pinker 1984), that the principles of Universal Grammar are in place from the earliest stages of acquisition. Instead, Borer and Wexler proposed that at least some principles undergo a process of maturation and may not be operative until quite late. In the case of the passive, they suggest that young children can derive adjectival participles in the lexicon, but that until the age of about four years they lack the principles required for NP-movement and so cannot form true verbal passives.

Since Borer and Wexler's original proposal, a slow stream of studies has steadily eroded the empirical foundations on which they built the maturation hypothesis. Allen and Crago (1994) have shown for Inuktitut, and Demuth (1989) for Sesotho, that at least in some languages children do produce clear verbal passives well before three years. Eisenbeiss (1994) offers experimental evidence showing that children acquiring German actually overgeneralize the eventive reading for participles in certain contexts - just the opposite of what Borer and Wexler would seem 
to predict. Most recently, Fox and Grodzinsky (1998) have argued that English-speaking children's trouble with passives has nothing to do with the difference between verbal and adjectival participles but rather reflects an inability to use the $b y$-phrase to express the verb's implicit argument. Thus it appears that adjectival passives do not have to precede verbal passives in development, and the new wisdom suggests that verbal and adjectival passives should in fact appear simultaneously in development.

In this article we present evidence which strongly supports the old conventional wisdom. Our data, based on an exhaustive analysis of seven longitudinal corpora, reveal a consistent pattern in children's spontaneous productions of passive participles. Early uses of participles, starting with children's earliest word combinations, are consistently adjectival and stative, as in example (3). Only much later are participles used to denote the actual events which can cause such states, as in (4).

(3) a. car broken.

b. pumpkin stuck.

c. now it's fixed.

(Adam 2;4)

(Nina $2 ; 1$ )

(Peter 2;0)

(4) a. you don't like to be rolled into clay.

(Adam 3;11)

b. she likes to be hugged.

(Nina 2;11)

c. this was broken and I gotta fix it.

(Peter 2;9)

Because our data consists of spontaneous productions, it both reconfirms and complements earlier findings which relied largely on comprehension data. Indeed, our data show children using eventive participles much earlier than had previously been observed; but it also shows stative participles earlier still, and in much greater abundance.

Interestingly, while our results may vindicate the empirical claims of Borer and Wexler, the details of the development we observe do not obviously accord with the idea that acquisition is driven by the maturation of innate syntactic principles. Rather, we suggest that pragmatic factors affecting the process of semantic acquisition are ultimately responsible for the extension of stative participles to eventive uses. Crucially, this process unfolds gradually and follows a consistent pattern. After producing their first stative participles, but before producing any unambiguous eventive ones, children regularly begin to use participles in equivocal contexts, where they can be interpreted either as stative or eventive. In our analysis, this pattern of production suggests that children use equivocal contexts to extend their initial stative understanding of participles to an eventive meaning. Stative participles are learned first because they most reliably co-occur with the situations they denote in conversational interactions between adults and children. This developmental pattern, which can 
be understood as an instance of constructional grounding, as discussed in Johnson (1999), casts a fresh light on recent debates concerning the nature of Universal Grammar.

\section{Constructional grounding}

Constructional grounding is a phenomenon hypothesized to explain the relations between certain pairs of conventional linguistic signs, or symbolic units, in the acquisition process. In constructional grounding, contextbound occurrences of a relatively simple source construction serve as the basis for children's initial hypotheses about a more difficult target construction. This is possible because certain utterances that might count as instances of the source construction also exhibit important properties of the target, and so may be regarded as examples of that construction as well. Crucially, these utterances involve a natural inferential connection between a more salient meaning and a less salient one, and so help to focus children's attention on the latter. They therefore provide bridging contexts in which relatively abstract semantic-pragmatic properties can be associated with familiar formal patterns through a simple process of contextually motivated reanalysis. Source constructions may be easier to learn for a variety of reasons. In some cases they are simply more frequent than the target constructions to which they are related. In other cases, they have meanings that are relatively easy to demonstrate in the contexts of face-to-face interactions.

One example of constructional grounding discussed in Johnson (1999) involves English deictic and existential there-constructions (cf. Lakoff 1987). The deictic there, as in example (5a), is often accompanied by a pointing gesture, and serves to focus attention on the location of an entity or situation present in the context of an utterance. Deictics are easy to learn because they serve much the same function as the act of pointing, a gesture which children understand as early as 9 to 12 months (Bruner 1983; Baldwin 1991). The existential there, as in (5b), has a more abstract and less easily demonstrated meaning; it introduces an entity or situation into the discourse, but it says nothing about the presence or location of that entity. While the deictic there has clear referential import, existential there is essentially a textual device for managing discourse referents.

$$
\begin{aligned}
& \text { a. There's a hot air balloon! } \\
& \text { b. There's a meeting at noon. }
\end{aligned}
$$

(existential)

There is evidence, however, that children's initial understanding of the existential is derived from certain instances of the deictic - namely, those 
with indefinite NPs. These deictics serve the existential-like function of introducing a new entity or situation to an addressee's consciousness, but do so by locating it in the physical context of the speech act itself. Consider the sentences in example (6). Sentence (6a) is a clear example of a deictic; the definite marking on the NP indicates that the dog is assumed to be known to the addressee, and that the speaker could not therefore be intending to introduce the dog to the addressee's consciousness. Example (6c), on the other hand, is a clear instance of an existential; the indefinite NP indicates that the dog is assumed not to be known to the addressee, and the past tense indicates that the dog is not immediately present in the context of the utterance. Example (6b), however, can be construed either as a deictic or an existential, and in fact has properties of both simultaneously; it serves to introduce the dog to the addressee's consciousness by pointing the dog out in the context of utterance.

(6) a. There's the dog over there.

(clear deictic)

b. There's a dog over there.

(overlap)

c. There was a dog in the yard.

(clear existential)

The examples in (7) illustrate a similar kind of bridging context between stative and eventive uses of the participle. Sentence (7a) clearly describes a present state of the child, and (7c) can only refer to a past event. Example (7b), however, combines properties of both: it could refer to a future scaring event or to a future state of being scared.

(7) a. The child is scared.

b. The child will get scared if you do that.

c. The child got scared by the loud noise.

(clear stative)

(overlap)

(clear eventive)

Utterances like (6b) and (7b), and the situations that they describe, provide children with an opportunity to associate a new meaning and pragmatic function with a constructional form that they already understand and use. By reanalyzing (6b) slightly, for example, children are able to form a highly accurate hypothesis about the form and meaning of the existential construction. In this reanalysis, the word there loses its locative meaning and takes on, in the context of the clausal form characteristic of deictics, the function of signaling an intent to introduce a new entity into consciousness.

\section{The construction of passive participles}

Since a construction is, by definition, a pairing of form and meaning (Goldberg 1995; Kay and Fillmore 1999), the acquisition of any construction naturally consists of two parts: the mastery of a linguistic form and the association of that form with some semantic content. 
A plausible view of this process as it applies to passive participles might include a series of small steps leading children from a few rote-learned participles to a general participle construction. First, starting in the oneword stage, children may learn some participial forms without necessarily associating them with verbs at all. Only later will children become aware of the relations between participles and the verbs they derive from. At least to begin with, they will do this on a case by case basis, making connections between individual items like break and broken, fix and fixed, and finish and finished. Gradually, as they become aware of these connections, they may abstract the general morphological patterns needed to derive participles from verbs productively. Finally, once they have become aware that there is a regular relationship between participles and verbs, they can begin to abstract the general syntactic and semantic features which govern this relationship. Only when they have established that participles instantiate a regular construction can they begin to sort out the complexities of the construction's rich semantics.

In our analysis, stative participles serve as the source construction in a process of constructional grounding, and eventive participles are the target. Two types of equivocal uses may serve as bridging contexts from stative to event meanings. The first type involves the use of participles in get passives, where the auxiliary get itself contributes an eventive regarding to the construction as a whole. The second type involves the use of participles in reference to past or future changes of state. Consider the examples in (8).

(8) a. The spinach is cooked.

(stative)

b. The spinach needs to be cooked.

(overlap)

c. The spinach was cooked by Mommy.

(clear eventive)

Example (8a) is a clear assertion about the current state of the spinach - namely, that it is in a state of being cooked. Example (8c) is a clear assertion about an event of cooking that took place in the past. Sentence (8b), however, can be construed either as an assertion about an event of cooking (what needs to happen to the spinach) or about a state of being cooked (the state the spinach needs to be in). The use here is equivocal rather than ambiguous because both construals are simultaneously valid. Utterances like these play an important role in acquisition, we argue, because they can be understood by children who assign only stative meanings to participles, but they suggest a particular linguistic encoding of a highly relevant eventive meaning as well.

Why should stative participles be easier to learn than eventive ones? We suggest it might be because stative participles reliably co-occur with the situations which they describe, and that this makes it easier for children to 
associate such forms with their meanings. The utterance of a sentence like (8a), for example, might well occur in a situation where the addressee was already aware of and interested in the state of the spinach, and so it would be easy to infer the stative meaning of the participle. Sentence (8c), on the other hand, cannot in principle co-occur with the cooking itself, and its meaning is consequently more difficult to infer in context. Of course, it is possible to produce an utterance such as The spinach is being cooked during a cooking event, more clearly demonstrating the eventive meaning of the participle; but most events do not lend themselves to this kind of running narration and so most eventive participles do not occur in such ideal contexts. With stative participles, on the other hand, co-occurrence between the word and the described situation seems to be the norm, and it is this reliable co-occurrence which we claim facilitates their early acquisition.

The early preference for stative over eventive meanings is reminiscent of the observation that children early in development are often more sensitive to the aspectual properties of verbal inflections than to their temporal properties (Bloom et al. 1980; Shirai and Andersen 1995). Antinucci and Miller (1976), in particular, found that young children learning Italian treat past participles as adjectival predicates, associating their use in the passato prossimo with the idea of a resultant state before generalizing the category to cover past events and activities more generally. There thus seems to be a solid empirical basis for supposing that stative relations are somehow particularly salient to young children. We should stress, however, that in our view the reason for this is not that states themselves are conceptually simpler than events; rather, they are, in a certain sense, symbolically simpler. Because states are stable, they are more likely to hold at the instant they are referred to, and the symbolic problem of associating a form with a meaning is made easier if the form reliably co-occurs with the entities to which it refers. In effect, the explanation we propose here is in many ways parallel to that offered by Gentner (1982) for why nouns should be easier to acquire than verbs.

Once children have established a construction for stative participles, they must somehow come to terms with uses where the participle has an eventive meaning, as in example (8c). At this stage, children may at least sometimes correctly infer the intended meaning of such utterances from context; the real problem is how they learn to associate this meaning directly with the participle itself. The use of participles in equivocal contexts helps here since these uses make a natural connection between the stative and eventive readings. For example, the stative reading for a sentence like (8b), "that the spinach needs to be in a cooked state", itself entails the eventive reading, "that the spinach needs to undergo cooking". 
Thus as children come to master these equivocal constructions, they may gradually learn to associate the use of passive participles directly with an eventive entailment, and as this association gains in strength, children may extend their use of participles to unequivocally eventive contexts like (8c). It is in this sense that the equivocal uses provide a bridge from an early acquired stative meaning to the later eventive meanings of the participle. In more general terms, constructional grounding exploits natural inferential connections to focus a learner's attention on specific abstract meanings and anchor them to specific linguistic forms.

In accordance with our general view of participle acquisition, we make two major predictions about the developmental pattern that children should follow. First, since it is necessary for them to construct "participle" as a morphosyntactic category before being able to recognize a systematic relation between (active) verbs and participles, they should begin to master the morphosyntactic relation between participles and verbs before they extend the participle category to truly eventive, verbal uses. Second, children's earliest uses of participles should be consistently stative in meaning, and children should produce equivocal uses of participles, which share properties of stative and eventive uses, before producing any unambiguous eventive participles.

\section{Data and methodology}

To test these predictions, we examined the passive participles found in seven corpora of children's spontaneous speech from the CHILDES archive (MacWhinney 1995). Because there is no simple way to automatically search for passive constructions in an unparsed corpus, the data for this study had to be gathered essentially by hand. This was done in the process of preparing the corpora for a larger coding project, the ReVerb project (Israel et al., in progress), which aims to provide a comprehensive account of the development of verbal constructions, including argument structure, auxiliary and complement constructions, in children between the ages of approximately 1;6 and 5 years. The seven corpora used for ReVerb and for the present study are listed in Table 1.

Because ReVerb aims to account for every instance of every construction it covers, each of the corpora were prepared so that every instance of every lexical verb could be coded. For each corpus, a complete set of "verb files" was created, each containing every instance of a given verb found in that corpus. These verb files were then manually searched, and every utterance with anything resembling a passive participle or a passive construction was extracted. While this process was labor intensive, it was the only way we could be sure of finding every passive 
participle, including those from unlikely verbs or with noncanonical morphology: for example, I don't wanna be get (Abe 2;11), there I get it fix (Eve 2;1), and it's all scribbly up (Sarah 4;11), among others.

The fruits of these labors are summarized in Table 2. "PP tokens" reflects the total number of utterances with a passive participle, excluding immediate verbatim imitations and repetitions within a stretch of text where the same construction is used to describe the same situation. "PP types" reflects the total number of distinct transitive verbs which surface as a passive participle in each corpus.

For the purposes of this study, a passive participle is defined as any intransitive nonfinite predicate which is systematically related to a transitive lexical verb, and whose subject argument denotes the participant role normally expressed by the underlying verb's internal (direct object) argument. In collecting our participles, we felt it best to err on the side of inclusion and so our criteria were fairly generous. In order to be included, a given form had to meet at least one of three criteria: ( $i$ ) it should display clear passive morphology (e.g., broken, finished, frozen, scared); (ii) it should be used with a clearly passive argument structure (as in that's all eat, Nina 2;4); or (iii) it should combine with an auxiliary in an unambiguous passive construction (as in I like get hurt, Adam 2;11).

Table 1. The seven corpora of the ReVerb project

\begin{tabular}{lccl}
\hline Child & Age range & Total sessions & Reference \\
\hline Abe & $2 ; 5-5 ; 0$ & 210 & Kuczaj 1976 \\
Adam & $2 ; 3-5 ; 2$ & 55 & Brown 1973 \\
Eve & $1 ; 6-2 ; 3$ & 20 & Brown 1973 \\
Naomi & $1 ; 3-4 ; 9$ & 93 & Sachs 1983 \\
Nina & $1 ; 11-3 ; 4$ & 56 & Suppes 1974 \\
Peter & $1 ; 9-3 ; 2$ & 20 & Bloom et al. 1974 \\
Sarah & $2 ; 3-5 ; 1$ & 139 & Brown 1973 \\
\hline
\end{tabular}

Table 2. Passive participles (PP) in our corpus

\begin{tabular}{lcc}
\hline Child & PP tokens & PP types \\
\hline Abe & 360 & 88 \\
Adam & 309 & 74 \\
Eve & 41 & 20 \\
Naomi & 68 & 31 \\
Nina & 149 & 46 \\
Peter & 209 & 40 \\
Sarah & 120 & 51 \\
\hline
\end{tabular}


Of these three, the morphological criterion is by far the weakest, and was overridden in cases where apparently passive morphology marks an intransitive verb (e.g., as in She's gone) or where it did not produce any change in argument structure (as in I'm finished or we're done). ${ }^{1}$ Also excluded were a number of common forms which are clearly passive in form, but which do not regularly alternate with an active verb in colloquial usage or, more to the point, in the ReVerb corpora: examples include tired, crowded, interested, supposed to, born, and disappointed.

Once we had collected apparently every instance of a passive participle in each of the seven corpora, the next task was to sort them in some meaningful way and to see what developmental patterns might be found in them. To this end, the participles were coded according to three basic criteria: (i) their morphological form; (ii) the type of construction in which they occurred; and (iii) their status as semantically stative, eventive, or equivocal. The goal of the morphological coding was to find evidence of productivity in the form of overregularizations and novel forms like brokened and eated. The constructional coding allowed us to sort participles according to the auxiliaries (be and get) and other verbs (e.g., make, want, have, keep, need, among others) with which the participles occurred. And finally, the semantic coding aimed directly at testing the constructional grounding hypothesis that stative uses should precede eventive uses, and that equivocal uses should be observed before the emergence of unambiguous eventives.

Although in most cases the distinction between stative, eventive and equivocal uses was intuitively clear, we did rely on explicit criteria to sort them out. In order to count as stative, a participle first of all had to clearly denote a state: the sort of situation that might result from an event or activity. This ruled out forms like carried and hugged which involve events or activities that do not produce a lasting, observable effect. Furthermore, to count as clearly stative, a given use had to denote an ongoing situation. The clearest examples are uses with a nonhabitual present tense, as in it's broken or this is fixed. Another diagnostic of stativity is the use of an adverbial like all, as in Sarah's all scrambled on that side (Sarah 4;4), or so, as in Adam's Daddy's gonna be so excited (Adam 4;3). Especially for the younger children, many examples involve participles occurring without any matrix verb or auxiliary, and thus without any overt tense marking. Such cases were coded as stative only where the context makes it clear that the participle denotes an on-going, present situation. For example, where Adam responds to his mother's question "What kind of truck is it?" with "Car broken. Truck broken, Mommy" (Adam 2;4), we analyze broken as stative because the context suggests that he is describing the truck's current state rather than reporting on something which happened to it. Finally, 
in those cases where a participle occurs without a matrix verb and the context fails to disambiguate its meaning, we simply treat the participle as unclear and uncodable. ${ }^{2}$

In order to count as a clear eventive, a participle had to occur in a construction where the eventive meaning could not be ascribed to any element other than the participle itself. In essence, our question was this: when do children learn that the imperfective copula be can combine with the normally stative participial form of a verb to denote a perfective event? We used four basic criteria to distinguish clear eventive uses of the participle. First, as a corollary to the principle that statives must denote a state, any participle which does not must be eventive. Examples of this sort include utterances like she likes to be hugged (Nina 2;11) and I want to be shooted (Adam 3;8). Tense and aspect marking can also make it clear that a participle must refer to an event or an activity. Thus progressive marking, as in I saw the cows being milked (Adam 3;10), is incompatible with stative predicates and so requires an eventive participle. Similarly, markers of iterativity like again as in It has to be dried again (Sarah 5;1) only apply to events or activities since only events or activities can be repeated. Finally, perhaps the clearest diagnostic for eventive participles involves the use of past tense marking in situations where a state persists in the present. Thus when Peter $(2 ; 9)$ says this was broken and I got to fix it he has to be referring to the breaking event because the broken state clearly still obtains.

Participles were coded as equivocal in cases where both the stative and the eventive interpretations are relevant and applicable to a given utterance. We distinguish two broad types of equivocal uses for passive participles. First, participles occurring in constructions with get, either in get-passives or get-causatives, were uniformly coded as equivocal. The get-constructions form an important bridging context for participles because they work with stative predicates generally-both adjectives (as in he's getting mad, Nina 2;4) and locatives (as in I'm gonna get back in my bed, Naomi 2;11)_but the construction as a whole denotes a change of state. A sentence like she got broken (Adam 3;1) thus counts as equivocal because while the participle itself simply denotes an end-state, the sentence as a whole describes the event that produced that state.

The second type of equivocal context involves uses without get where the participle denotes a past or future state. For example, in utterances like they're gonna be broken (Naomi 3;5) or I'm not gonna be scared (Peter 2;11), the participle denotes a state resulting from some future event, and so both the stative and the eventive readings apply equally. This sort of equivocation regularly applies to the interpretation of participles in the small clause complement of verbs like want or need, as can be 
seen in utterances like do you want yours cut? (Adam 3;2) and she doesn't need it cut (Nina 3;1). Uses with the past tense can give rise to similar effects: thus a sentence like door was locked (Sarah 3;10) may refer equally to an event of locking or to the state of being locked that ensued from it.

\section{Results-1: Morphosyntactic development}

In assessing the children's morphosyntactic development the goal was to see whether children showed evidence of productivity with the participle category before they extended the stative semantics of the category to eventive uses. Two diagnostics were used to assess children's productivity with passive participles: alterations between the participle and other forms of a single verb, and the creative use of morphology in forming novel participles.

Cases in which a given verb is used with the same sense both as a passive participle and in some active construction within a reasonably short period of time were counted as alternations. Ideally, the two uses should occur on the same day, and preferably in the same stretch of discourse, though in fact, we used a fairly liberal standard and sometimes counted alternations separated by several days. We counted as novel participles forms like stucked, hurted, and holden in which the participial morphology is used in a way that the children are unlikely to have heard from other speakers. Some children also showed signs of creative zero-derivations (e.g., that's all eat Nina 2;4); however, these were excluded since they do not involve any obvious overgeneralizations.

Table 3 summarizes the results for all seven children. We assume the use of a construction with at least two different verb types as a minimal measure of productivity, and so the numbers listed for stative and eventive passives represent the age, rounded to the nearest month, by which a given child had produced at least two participles of the relevant

Table 3. Stages in the morphosyntactic development of participles

\begin{tabular}{llllllll}
\hline & Abe & Adam & Eve & Naomi & Nina & Peter $^{\text {a }}$ & Sarah \\
\hline Stative passives & $2 ; 6$ & $2 ; 4$ & $1 ; 8$ & $1 ; 11$ & $2 ; 1$ & $1 ; 11$ & $2 ; 6$ \\
Alternations & $2 ; 6$ & $2 ; 4$ & $2 ; 0$ & $1 ; 11$ & $2 ; 5$ & $2 ; 0$ & $2 ; 6$ \\
Novel participles & $3 ; 0$ & $3 ; 3$ & - & $2 ; 11$ & $3 ; 2$ & $1 ; 10$ & $3 ; 3$ \\
Eventive passives & $2 ; 11$ & $3 ; 7$ & - & $4 ; 8$ & $3 ; 0$ & $2 ; 9$ & $4 ; 11$ \\
\hline
\end{tabular}

${ }^{\text {a }}$ There is an apparent paradox in Peter's data, as the table shows him producing novelly inflected participles before he has stative passives. Peter's first passive participle was broken, transcribed variously as brokes, broken, and brokened in file PETERO3, when he was 1;10.15. Only in the next session, at 1;11.07, did Peter use his next two participles, shut and finished. 
type. Since alterations and novel participles are themselves diagnostics of productivity, the ages for these cells represent the children's first instances for each of these categories. A representative sample of the data, including the earliest instances for each category, is presented in the Appendix.

All of the children produced stative participles more or less from the earliest stages of recording, and all of the children go for a considerable period before they produce any eventive participles, often more than a year. The results suggest that children begin to derive participles productively before they learn to use them with eventive semantics: all of the children show an ability to alternate between active and passive forms of a verb well before they produce any eventive passives; and only two children, Abe and Nina, use eventive participles before producing novelly inflected participles.

We view these results as a robust confirmation of our basic prediction that children must learn that there is a participle construction in their language before they can learn the complex polysemy associated with that construction.

\section{Results-2: Semantic development of participles}

In assessing the children's semantic development our goal was to see whether children would produce equivocal uses of participles before they extended the stative semantics of the category to eventive uses. We distinguish two categories of equivocal uses. "Get-constructions" include all uses of a participle in a get-passive or get-causative, where get itself contributes an eventive meaning to the construction as a whole. "Equivocal events" include all cases in which the future or past reference of a construction effectively makes both the change-of-state eventive reading and the resultant-state stative reading equally relevant to the interpretation of the utterance. In Table 4, the numbers in each cell represent the age at which a child has used at least two distinct verbs in a construction of the relevant type. Again, a representative sample of the data is presented in the Appendix.

Table 4. Stages in the semantic development of participles

\begin{tabular}{llllllll}
\hline & Abe & Adam & Eve & Naomi & Nina & Peter & Sarah \\
\hline Stative passives & $2 ; 6$ & $2 ; 4$ & $1 ; 8$ & $1 ; 11$ & $2 ; 1$ & $1 ; 11$ & $2 ; 6$ \\
get-constructions & $2 ; 8$ & $2 ; 5$ & $2 ; 1$ & $3 ; 4$ & $2 ; 3$ & $2 ; 6$ & $3 ; 2$ \\
Equivocal events & $2 ; 9$ & $3 ; 0$ & $2 ; 1$ & $3 ; 5$ & $2 ; 11$ & $2 ; 11$ & $3 ; 10$ \\
Eventive passives & $2 ; 11$ & $3 ; 7$ & - & $4 ; 8$ & $3 ; 0$ & $2 ; 9$ & $4 ; 11$ \\
\hline
\end{tabular}


The results bear out the basic prediction of the constructional grounding hypothesis, that equivocal uses should precede clear eventive passives. All seven of our subjects use passive participles in get-constructions well before they begin to produce true eventive passives. And all except for Peter use participles in equivocal events before producing eventive participles. Six subjects thus robustly confirm our predictions, and all seven show a development which is essentially consistent with those predictions.

Peter's data deserves a comment here. As the Appendix shows, Peter produces only two eventive passives in his entire corpus, but the first of these, at age 2;3.21 (i.e., two years, three months, and twenty-one days), actually comes before any equivocal uses. This seems to undermine our hypothesis, but in fact, it seems likely that this utterance-They're not supposed to be eaten anyway, said to Peter's younger sister-may have been something Peter heard before and was repeating verbatim. This conjecture seems plausible given that the sentence is strikingly more complex than anything else Peter is saying at this age, and it is precisely the sort of thing which adults will frequently say to very young children. In any event, Peter only produces one other eventive passive in the whole corpus, and this comes a full six months later. Thus despite his one singularly precocious utterance, Peter, like our other subjects, appears to use participles productively in equivocal contexts before regularly extending them to eventive passives.

On the whole, the general consistency across subjects is remarkable, especially given the significant differences among them as to when they reach our various milestones. In general, these sorts of individual differences seem to suggest that children are learning the categories involved: if it was just a matter of biological maturation one might not expect such variation. Moreover, it is worth noting that while six of our subjects do produce at least one or two eventive passives, only three children-Abe, Adam and Nina-really use the construction with any regularity. Interestingly, as the data in the Appendix suggest, these three are also among the most prolific subjects in their use of get-constructions and other equivocal participles - a fact which seems to underscore the importance of equivocal uses in the emergence of eventive passives.

\section{Discussion}

If nothing else, our results should help to settle the basic empirical question of whether stative uses of the English passive participle do or do not precede the appearance of true verbal passives in early child language: they 
do. In this sense, our data vindicate Borer and Wexler's claim that the grammar of passives matures over time, and it poses a challenge for proponents of the continuity hypothesis, who claim that it does not. And yet our data also suggest a story crucially at odds with a basic assumption of both the maturation hypothesis and the continuity hypothesis - that the grammatical principles needed to acquire the passive construction could not be learned, and must therefore somehow be given to the child in the form of an innate biological endowment. This, of course, is the central assumption of all nativist accounts of language acquisition.

Our data suggest that learning may in fact play an important role in the acquisition of passive constructions. In particular, we have argued that the participle's shift from stative to eventive uses can be explained by the logistics of learning form-meaning pairings, and by the ways in which different meanings become available for encoding by specific formal patterns. Our evidence points to a regular process whereby children build on their knowledge of adjectival, stative participles to learn the properties of eventive, verbal passives. Children's earliest uses of participles are functionally and distributionally indistinguishable from their use of adjectives. The extension from stative to eventive uses depends on the occurrence of participles in contexts where both meanings are somehow relevant. In these equivocal contexts, the participle contributes its stative meaning to the construction of a sentence whose meaning as a whole denotes an actual change of state. These utterances are easy to interpret because they are compatible with the child's stative understanding of the participle; but their dynamic meaning also paves the way for a new interpretation, allowing the child to attribute the eventive meaning of the sentence as a whole to the participle itself.

In fact, the development we observe here may reflect a basic strategy children use to deal with polysemy in general. Constructional grounding allows children to acquire new constructions by exploiting the systematic sense relations which characterize polysemy networks. On this view then polysemy, which normally seems to pose a challenge for learning, may actually make the learning process easier.

The data we have presented is remarkably consistent with the predictions of constructional grounding. All seven of our subjects use participles in get-constructions before they produce eventive passives, and all but one use participles in other equivocal contexts before their first eventive passives. This pattern is quite unexpected given the basic assumptions of both the maturation and the continuity hypotheses. It suggests that rather than simply activating an innate formal principle, children might acquire the passive by gradually mastering different aspects of its form and meaning. 
On our account, the acquisition of passive participles consists largely of learning, on the basis of input utterances, the semantic properties that distinguish true passive participles from stative predicates. The stage of equivocal uses we observe suggests that children extend their initially stative understanding of participles to accommodate relevant eventive meanings on the basis of specific utterances that they encounter. The acquisition process is thus consistent with a usage-based view of grammar (Langacker 1991) in which grammatical representations are abstracted from and continuously modified by the particular usage events in which they are experienced. Stative participles are learned first, we argue, because they regularly co-occur with the states they denote and are therefore especially amenable to simple ostension, on which the earliest stages of the schematic abstraction of symbolic units must be based. Eventive meanings first become easily accessible to children in utterances in which they co-occur with and bear a strongly motivated relation to specific stative meanings.

Our results are consistent with, and in fact help explain earlier observations in the literature on the acquisition of passives. They clearly support Horgan's basic observation that children's early passives are "almost exclusively after-the-fact observations on the state of things" (1978: 68), as well as the experimental findings of Maratsos, Fox, Becker, and Chalkley (1985) that children have a much easier time understanding passives in which the participle denotes the observable result of some action. The reason for this, we have suggested, is that because states are easy to observe, it is comparatively easy to associate stative meanings with the forms that express them.

The account we offer is also consistent with the observation that the acquisition of passives may look very different in languages other than English. Because the constructional grounding hypothesis depends on overlapping properties of conventional form-meaning pairings, the predictions it makes depend crucially on the constructional inventory of any given language. In particular, in languages where adjectival and verbal passives are formally distinct, as in German (Eisenbeiss 1994; Fritzenschaft 1994), or where there is no adjectival passive, as in Sesotho (Demuth 1989), we make no prediction that stative uses of the participle must precede eventive uses, or that verbal passives should appear late in development.

The Dutch passive, on the other hand, is a more interesting case, since it is similar in many ways to its English cousin. As Verrips (1996) points out, Dutch passive participles occur in constructions with the verb zijn 'to be' which are ambiguous between a present tense adjectival passive and a perfective verbal passive. All things being equal, our account 
predicts that Dutch children should master the adjectival constructions before the verbal ones, just as happens in English. Verrips (1996) addresses this question using an elicited imitation task. She argues that Dutch children actually treat all participles as verbs; however, as she herself concedes, her results are less than conclusive for children younger than five years old. Since our own data suggest that children as young as three years of age may be well on the way to mastery of the verbal passive, the earlier preference for stative passives may be difficult to detect experimentally. Rich corpus data for the period between two and three years might help to settle the question.

At issue in our account of participle acquisition are some of the fundamental questions for any theory of language: whether and how grammatical categories can be learned. A standard, if somewhat pessimistic, view holds that grammatical categories are defined purely in terms of their combinatoric properties, and cannot be induced from the input children receive. On this view, categories like noun and verb are understood as primitives of an innate and specifically linguistic cognitive endowment (Hyams 1986; Crain 1992). Nativism follows directly from the assumption that a grammar consists essentially in a set of combinatoric properties which specify the nature of a well-formed syntactic string.

In our view, and in the tradition of cognitive linguistics more generally, grammatical categories are symbolic in nature and are defined by the regular association of an experienced conceptual content with an experienced linguistic form. Acquisition itself is a process by which children learn to associate particular conceptual contents (i.e., meanings) with particular patterns of expression (i.e., forms). On this account it is not surprising to find that the formal and semantic properties of participles emerge through a gradual learning process, as our data suggest they do. Moreover, our data suggest that this process reflects the nature of the conceptual categories in question, motivated relations between those categories, and the pragmatic factors that make some conceptual categories more accessible to early linguistic encoding than others.

Obviously the data we have presented cannot begin to settle the question of how much grammar must be innate and how much might be learned. Certainly, there are aspects of the English passive which our data does not explain. For example, as Fox and Grodzinsky (1998) note, the use of the $b y$-phrase poses a set of problems quite distinct from those involved in mastering the eventive use of passive participles. But our data does suggest that children do learn important aspects of the English passive construction based on their everyday experiences with its use. Of course, nativists are correct in pointing out that certain grammatical principles are simply too abstract to be learned on the basis of positive input alone. 
The real question is whether children actually need such abstract principles to learn their language. Our data suggests that they may not. Rather, the categories children actually need to master a language, like the distinction between stative and eventive uses of the participle, may be learned on the basis of children's specific experiences with specific constructions. Clearly, children may learn a great deal by paying attention to the particular ways constructions are used; in order to find out just how much children might learn this way, researchers will need to pay particular attention to the ways children themselves use the constructions they are learning.

Received 15 February 2000

Revision received 7 September 2000
Max Planck Institute for Evolutionary Anthropology Leipzig, Germany Soliloquy Inc., New York City University of New York

\title{
Appendix: Seven developmental profiles
}

\author{
1. Abe
}

Stative predications (204 tokens)

it's broken.

and it's all dried out Daddy.

Mom, why this is glued?

\section{Alternations}

somebody broke it. I want paper.

this is broken, Mom.

what that's cut, all cut?

you cut those.

ok I can crack them.

uhhuh funny and silly Daddy, those things are cracked.

Novel participles

no I was just teasing you I don't wanna be get. 
Get-constructions (111 tokens)

Momma, that's getting done.

I better put them in before they get broken.

Mommy, how this is, got glued, Mom?

you fall down from there, you will get hurt.

we should've told him you put bananas on the floor they will get bruised.

\section{Equivocal events (25 tokens)}

that's gonna be mine taco that's gonna be broken taco.

yeah mommies, mommies uh be scared like daddies.

I said I wanted to play a game pretty soon and how long my, our game will be finished?

Daddy, fix my bunny see this part needs to be fixed.

Clear eventives (18 tokens)

no I was just teasing you I don't wanna be get.

do you want ta be horned?

$\begin{array}{ll}\text { I'm trying to get this up so high so I won't be hurted when I jump. } & 3,2.29 \\ \text { are we gonna go to that burned fire store that was all burned. } & 3: 4.19\end{array}$

no a monarch butterfly was killed by a bird.

\section{Adam}

Stative predications (201 tokens)

car broken.

all finished?

it's fold up.

\section{Alternations}

car broken.

break suitcase.

it's fold up.

fold it. fold it, fold it.

Novel participles

it's fold up.

dat one knock down.

it's broked. 
Get-construction (50 tokens)

get stuck.

get hurt, nail.

I like get hurt.

she got broken.

I got stuck with the knife.

Equivocal events (33 tokens)

I can let it spilled.

I going be excused.

I going make it all fix.

do you want yours cut?

Clear eventives (11 tokens)

if I put dis \# is [?] it been broken?

dat dolly was made in Italy.

dis been wrapped on here.

You shoot me. I want to be shooted.

saw the cows being milked.

$3 ; 10.14$

how could it go up if it's not flyed?

$3 ; 10.15$

\section{Eve}

Stative predications (27 tokens)

all, all, all done, again.

it broken.

milk all wiped up.

Alternations

it all closed up.

I have close the door.

it got smoothed, Fraser.

I smoothing it.

there I get it fix.

I fix it.

Novel participles (0 tokens)

Get-constructions (5 tokens)

see if you can get it untied. 
and they got folded up.

we had to get our shoe caught.

Equivocal events (1 token)

this is to be folded?

Clear eventives (0 tokens)

4. Naomi

Stative predications (55 tokens)

broken haha.

is it fixed?

is it broke?

is locked?

\section{Alternations}

is it broke?

you broke it.

is it fixed?

I fixing.

is locked?

I'm locking the door.

Novel participles

no that is teared.

oh, this is teared off.

Get-constructions (4 tokens)

he got stuck in there.

I didn't get my shirt caught.

I wanna get something dumped out.

you can get dressed now.

Equivocal events (3 tokens)

could be stopped.

Clear eventives ( 2 tokens)

did you see how that airport was made? 
5. Nina

Stative predications (103 tokens)

pumpkin stuck.

called king.

that's fixed.

it's all finished.

\section{Alternations}

I better cook egg for you, ok?

it's not cooked.

cover your eyes up.

I'm all covered too.

I was scaring her.

cause I get scared.

Novel participles

that's all eat.

is break ... is broken.

they're stucked on the boat.

Get-constructions (24 tokens)

get hurt.

it get twisted.

I wanna get dressed.

cause I get scared.

$2 ; 5.25$

they got frozen.

Equivocal events (13 tokens)

he's gonna be scared.

she wants to be wrapped in them.

I want them opened.

she doesn't need it cut.

and some snakes were wrapped together.

I want that zippered up with that in it.

Clear eventives ( 7 tokens)

she likes to be hugged.

what would happen when I will be cooked in a pot? 


\section{Peter}

Stative predications (167 tokens)

hm \# broken \# broken.

door shut.

all finished.

it's put in there microphone.

\section{Alternations}

you fix it.

now it's fixed.

I break em.

it's broken.

yeah, I gonna lock that.

the door was locked ... you lock it.

Novel participles

xxx brokened xxx.

broked.

and they're falled over.

Get-constructions (11 tokens)

record got broken.

he didn't get hurt.

I can't get fixed!

$2 ; 9.14$

they won't get lost.

$2 ; 10.21$

Equivocal events (5 tokens)

the door was locked. you lock it.

I'm not gonna be scared.

they're gonna be scared.

$2 ; 10.21$

we had it taped over here.

$2 ; 10.21$

Clear eventives ( 2 tokens)

they're not supposed to be eaten anyway.

this was broken and I got ta fix it.

\section{Sarah}

Stative predications (77 tokens)

I be filled. 
light broken.

hmm, 〈you tell me $\rangle[/ /]$ it's called?

\section{Alternations}

broken.

I broke it.

no, I coloring.

here colored.

come on, I got wash em.

have be wash.

Novel participles

ooh, he hurted.

it's breaked.

he get died.

Get-constructions (25 tokens)

she's going to get married.

I got a twisted.

it was get burned on my sore finger.

hey I won't get hurt by puddles.

Equivocal events (9 tokens)

he not invited.

door was locked.

it's going to be green egg when colored.

gonna be burn down.

i'm making her picture scribbled.

Clear eventives (3 tokens)

this piece was ripped in half.

my finger was caught ... see, it's caught.

cause it has to be dried again, huh?

\section{Notes}

* Earlier versions of this work were presented at the 2000 Meeting of the Linguistics Society of America in Chicago, and at the workshop "Building Structure from Ontogeny", held at the Max Planck Institute for Evolutionary Anthropology in Leipzig, May 2000. While working on this project, Christopher Johnson was affiliated with the FrameNet Project at the International Computer Science Institute in Berkeley, CA, and was a visiting researcher of the Proteus Project at New York University. He would like to thank Charles Fillmore, Catherine MacLeod and Ralph Grishman for their support during this period. 
The authors thank Heike Behrens, Melissa Bowerman, Holger Diessel, Elena Lieven, Brian MacWhinney, Lise Menn, Michael Tomasello, and Angelika Wittek for helpful comments and discussions. What inadequacies remain in this work are entirely our own responsibility.

Michael Israel can be contacted at the Max Planck Institute for Evolutionary Anthropology, Leipzig, Germany. E-mail: israel@eva.mpg.de

Christopher Johnson can be reached at Soliloquy Inc., New York, NY. E-mail: cjohnson@soliloquy.com

Patricia J. Brooks is contactable via the College of Staten Island of the City University of New York. E-mail: pbrooks@postbox.csi.cuny.edu

1. Some of the forms thus excluded may in fact offer hints to the children's emerging understanding of passive morphology. In particular, we note that several children extended participle marking to unaccusative predicates like fall (I'm fell, Peter 2;4; It's felled, Adam 2;11), grow (maybe this got growned on it, Abe 3;11), die (he get died, Sarah 3;7, meaning just 'he died'), and born (What happened when you were borned, Abe 2;11; Is dat where I was borned? Adam 4;3). Such uses are rare, but they do suggest an early sensitivity to the thematic properties of passive subjects.

2. We found comparatively few examples which had to be left uncoded. There were, in sum, two examples for Abe, fourteen for Adam, eight for Eve, four for Naomi, two for Nina, twenty-four for Peter, and six for Sarah.

\section{References}

Allen, Shanley and M. B. Crago

1993 Early acquisition of passive morphology in Inuktitut. In Clark, E. (ed.), Proceedings of the 24th Child Language Research Forum. Stanford: CSLI, $112-123$.

Antinucci, Francesco, and Ruth Miller

1976 How children talk about what happened. Journal of Child Language 3, 169-189.

Baldwin, Dare A.

1991 Infants' contributions to the achievement of joint reference. Child Development 62, 875-890.

Bloom, Lois, L. Hood, and P. Lightbown

1974 Imitation in language development: If, when and why. Cognitive Psychology $6,380-420$.

Bloom, Lois, Karin Lifter, and Jeremie Hafitz

1980 Semantics of verbs and the development of verb inflection in child language. Language 56, 386-412.

Borer, Hagit and Kenneth Wexler

1987 The maturation of syntax. In Roeper, T. and E. Williams (eds.), Parameter Selling. Dordrecht: Reidel, 123-172.

Brooks, Patricia J. and Michael Tomasello

1999 Young children learn to produce passives with nonce verbs. Developmental Psychology 35, 29-44.

Brown, Roger

1973 A First Language: The Early Stages. Dordrecht: Kluwer. 
Bruner, Jerome

1983 Child's Talk: Learning to Use Language. New York: Norton.

Crain, Stephen

1992 Language acquisition in the absence of experience. Behavioral and Brain Sciences 14, 597-611.

Demuth, Katherine

1989 Acquisition of the Sesotho passive. Language 65, 56-80.

Eisenbeiss, Sonja

1994 Auxiliaries and the acquisition of the passive in German. In Clark, E. (ed.), Proceedings of the 25th Stanford Child Language Research Forum. Stanford: CSLI, 235-242.

Fox, Danny and Yosef Grodzinsky

1998 Children's passive: A view from the by-phrase. Linguistic Inquiry 29, 311-332.

Fritzenschaft, Agnes

1994 Activating passives in child grammar. In Tracy, R. and E. Lattey (eds.), How Tolerant is Universal Grammar, Essays on Language Learnability and

Gentner, Dedre Language Variation. Tübingen: Niemeyer, 155-184.

1982 Why nouns are learned before verbs: Linguistic relativity vs. natural partitioning. In Kuczaj, S. (ed.) Language Development, vol. 2: Language, Thought and Culture. Hillsdale, NJ: Erlbaum, 301-333.

Goldberg, Adele

1995 Constructions: A Construction Grammar Approach to Argument Structure. Chicago: University of Chicago Press.

Horgan, D.

1978 The development of the full passive. Journal of Child Language 5, 65-80.

Hyams, Nina

1986 Language Acquisition and the Theory of Parameters. Dordrecht: Reidel.

Israel, Michael, Patricia Brooks and Michael Tomasello

in progress The ReVerb Code Book. Technical manual, Max Planck Institute for Jespersen, Otto Evolutionary Anthropology, Leipzig, Germany.

1949 A Modern English Grammar, vol. 4. London: Allen and Unwin.

Johnson, Christopher

1999 Constructional grounding: The role of interpretational overlap in lexical and constructional acquisition. Ph.D. Dissertation, Linguistics Department, University of California, Berkeley.

Kay, Paul and Charles J. Fillmore

1999 Grammatical constructions and linguistic generalizations: The What's $X$ doing Y? construction. Language 75, 1-33.

Kuczaj, Stan

1976 -ing and -ed: A study of the acquisition of certain verb inflections. Unpublished manuscript, University of Minnesota.

Lakoff, George

1987 Women, Fire and Dangerous Things: What Categories Reveal about the Mind. Chicago: University of Chicago Press.

Langacker, Ronald W.

1991 Concept, Image, and Symbol: The Cognitive Basis of Grammar. Berlin and New York: Mouton de Gruyter. 
Levin, Beth and Malka Rappaport-Hovav

1986 The formation of adjectival passives. Linguistic Inquiry 17, 623-661.

MacWhinney, Brian

1995 The CHILDES Project: Tools for Analyzing Talk. Hillsdale, NJ: Erlbaum.

Maratsos, Michael, Dana Fox, Judith Becker, and Mary Anne Chalkley

1985 Semantics restrictions on children's passives. Cognition 19, 167-191.

Pinker, Steven

1984 Language Learnability and Language Development. Cambridge, MA: MIT Press.

Sachs, Jacqueline

1983 Talking about the there and then: The emergence of displaced reference in parent-child discourse. In Nelson, K. E. (ed.), Children's Language, vol. 4. Hillsdale, NJ: Erlbaum, 359-438.

Shirai, Yasushiro and Roger Andersen

1995 The acquisition of tense-aspect morphology: a prototype account. Language 71, 743-762.

Sudhalter, Vicki and Martin Braine

1985 How does comprehension of passives develop? A comparison of actional and experiential verbs. Journal of Child Language 12, 455-470.

Suppes, Patrick

1974 The semantics of children's language. American Psychologist 29, 103-114.

Verrips, Maaike

1996 Potatoes Must Peel: The Acquisition of the Dutch Passive. (Ph.D. dissertation,

University of Amsterdam.) The Hague: Holland Institute of Generative

Wasow, Tom Linguistics.

1977 Transformations and the lexicon. In Culicover, P. W., T. Wasow, and A. Akmajian (eds.), Formal Syntax. New York: Academic Press, 327-360. 
Copyright $\odot 2003$ EBSCO Publishing 